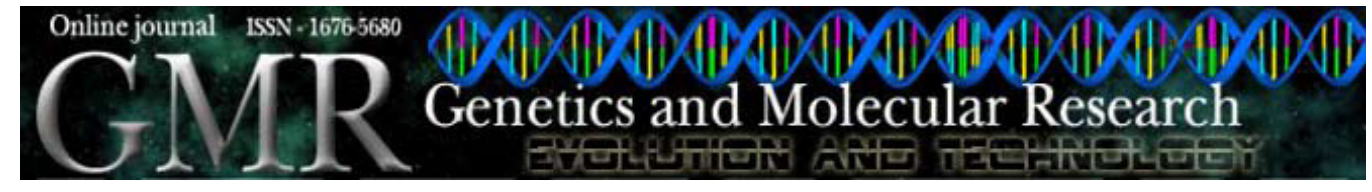

\title{
Determination of self-incompatibility groups of sweet cherry genotypes from Turkey
}

\author{
A. Ipek ${ }^{1}$, H. Gulen ${ }^{1}$, M.E. Akcay ${ }^{2}$, M. Ipek ${ }^{1}$, S. Ergin ${ }^{1}$ and A. Eris ${ }^{1}$ \\ ${ }^{1}$ Horticulture Department, Faculty of Agriculture, Uludag University, \\ Gorukle Bursa, Turkey \\ ${ }^{2}$ Ataturk Central Horticultural Research Institute, Yalova, Turkey \\ Corresponding author: A. Ipek \\ E-mail: maipek@uludag.edu.tr
}

Genet. Mol. Res. 10 (1): 253-260 (2011)

Received September 27, 2010

Accepted November 25, 2010

Published February 15, 2011

DOI 10.4238/vol10-1gmr1024

\begin{abstract}
Determination of S-allele combinations of sweet cherry genotypes and cultivars has importance for both growers and breeders. We determined S-allele combinations of 40 local Turkish sweet cherry genotypes using a PCR-based method. Ten different S-alleles were detected. Although the most common S-allele was $\mathrm{S}_{3}$, as also found in Western genotypes and cultivars, there were some differences in the frequencies of some S-alleles between Turkish and Western sweet cherry genotypes. According to their S-allele compositions, 30 local Turkish sweet cherry genotypes were assigned to 10 previously identified incompatibility groups. For the remaining genotypes, whose S-allele combinations did not fit to any previous incompatibility groups, three more incompatibility groups, XLII, XLIII and XLIV, were proposed. Results obtained from this study will help both sweet cherry growers and breeders to better manage these local Turkish sweet cherry genotypes in their orchards.
\end{abstract}

Key words: Sweet cherry; S-allele; Prunus avium L.; S-genotyping; Incompatibility groups 


\section{INTRODUCTION}

Turkey is a leading sweet cherry (Prunus avium L.) producer and exporter country in the world. In 2007, Turkey produced 392,000 metric tons of sweet cherry and exported 57,019 metric tons of this production (FAO, 2007). This significant sweet cherry production has been made using both local and introduced cultivars. Since Anatolia is an important origin and site for domestication of sweet cherry (Watkins, 1976; Gisbert et al., 2008), Turkey has many local sweet cherry cultivars and genotypes whose S-allele combination has not been determined yet. On the other hand, genetic relationships among local Turkish sweet cherry genotypes have been analyzed using DNA markers (Gulen et al., 2010).

During the establishment of new sweet cherry orchards, appropriate pollinators have to be planted to obtain an acceptable fruit set. To do this, cross-(in)compatibility between the major cultivar and pollinator(s) has to be determined prior to establishment of commercial sweet cherry orchards. In addition, determination of cross-(in)compatibility between cultivars is also important for cross breeding of sweet cherry when specific crosses between two cultivars are desired. Therefore, incompatibility groups of western sweet cherry genotypes have been determined with recent studies (Tobutt et al., 2004; Schuster et al., 2007; Gisbert et al., 2008).

Incompatibility in sweet cherry is controlled by multi-allelic S-locus and it is a gametophytic self-incompatibility system (Crane and Lawrence, 1929). In this system, selfincompatibility occurs by arresting pollen tube growth if both the haploid genome of pollen and the diploid genome of style carry the same S-allele. S-alleles in sweet cherry encode for stylar ribonucleases (S-RNase) that inhibit pollen tube growth in style by degrading pollen RNA (Boskovic and Tobutt, 1996; Boskovic et al., 1997).

Recent studies demonstrated that S-RNase genes in Prunus are composed of several conserved domains and two introns (Ushijima et al., 1998; Tao et al., 1999). Varying sizes of these two introns interrupting the coding region of S-allele genes have been successfully used to identify S-alleles in sweet cherry genotypes using a polymerase chain reaction (PCR)-based method (Tao et al., 1999; Sonneveld et al., 2001, 2003). Currently, this method has been extensively used for S-genotyping of S-alleles (S1 to S25) in sweet cherry by various studies (Wiersma et al., 2001; Wunsch and Hormaza, 2004; De Cuyper et al., 2005; Schuster et al., 2007; Gisbert et al., 2008). However, S-allele combinations of Turkish sweet cherry genotypes have not been previously determined by S-genotyping to our knowledge. In this study, S-allele combinations of local Turkish sweet cherry genotypes were determined using a PCR-based method for S-genotyping of sweet cherry.

\section{MATERIAL AND METHODS}

\section{Plant materials and DNA extraction}

A total of 40 local Turkish sweet cherry genotypes were analyzed in the study (Table 1). The young leaf samples of these genotypes were collected from a sweet cherry genetic resource orchard at the Atatürk Central Horticultural Research Institute in Yalova, Turkey, where Turkish sweet cherry germplasm is maintained. Genetic relationships among these lo- 
cal Turkish sweet cherry genotypes were determined using AFLP (amplified fragment length polymorphisms) and SSR (simple-sequence repeats) markers (Gulen et al., 2008, 2010). DNA samples were extracted from $150 \mathrm{mg}$ lyophilized and powdered young leaves of these genotypes using the modified CTAB protocol described by Futterer et al. (1995). The DNA concentration of leaf samples was measured by using a Qubit fluorometer (Invitrogen, Carlsbad, CA, USA) and adjusted to $20 \mathrm{ng} / \mu \mathrm{L}$. DNA samples were stored at $-20^{\circ} \mathrm{C}$ in TE buffer until use.

\section{PCR procedure}

Consensus primer pairs for amplification of introns I and II developed by Sonneveld et al. (2003) were used to amplify introns I and II of the S-RNase gene in local Turkish sweet cherry genotypes. Alleles of the S-RNase gene were also amplified using allele specific primer pairs for detection of S1-S16 alleles in local Turkish sweet cherry genotypes (Sonneveld et al., 2001, 2003). Each $25 \mu \mathrm{L}$ PCR for amplification of S-alleles consisted of 1 U DNA polymerase (Bioron, Ludwigshafen, Germany) with the reaction buffer supplied at $1 \mathrm{X}$ concentration, $0.2 \mu \mathrm{M}$ of each primer, $2 \mathrm{mM} \mathrm{MgCl}$, dNTPs at $0.25 \mathrm{mM}$ each, and $50 \mathrm{ng}$ template DNA. Thermal cycling conditions were 2 min at $94^{\circ} \mathrm{C}, 35$ cycles of $45 \mathrm{~s}$ at $94^{\circ} \mathrm{C}, 1 \mathrm{~min}$ at the appropriate annealing temperature for each specific primer pair (Sonneveld et al., 2001, 2003) and $2 \mathrm{~min}$ (4 min for amplification of intron II) at $72^{\circ} \mathrm{C}$ and a final extension step of $5 \mathrm{~min}$ at $72^{\circ} \mathrm{C}$. For these reactions, an Applied Biosystems Thermal Cycler was used. PCR products of intron II and S-alleles $\left(\mathrm{S}_{1}-\mathrm{S}_{16}\right)$ were separated on a $1.5 \%$ agarose gel (Sigma, St. Louis, MO, USA) in 0.5X Tris-borate (TBE) buffer, but the PCR product of intron I was separated on $2 \%$ agarose gel. Gels were stained with ethidium bromide $(0.5 \mathrm{mg} / \mathrm{mL})$ (Sigma) and photographed.

\section{RESULTS AND DISCUSSION}

In order to determine the S-allele composition of local Turkish sweet cherry genotypes, parts of the S-RNase gene spanning introns I and II were amplified with PaConsI and PaConsII consensus primer pairs, respectively (Sonneveld et al., 2003). The amplification of the S-RNase gene with the consensus primers flanking intron I enabled us to determine the sweet cherry genotypes carrying $\mathrm{S}_{3} \mathrm{~S}_{10}$, but the amplification of intron I was not enough to discriminate $\mathrm{S}_{4}$ from $\mathrm{S}_{6}, \mathrm{~S}_{1}$ from $\mathrm{S}_{5}$ or $\mathrm{S}_{2}, \mathrm{~S}_{7}, \mathrm{~S}_{9}$, and $\mathrm{S}_{12}$ from each other (Table 1; Figure 1). On the other hand, amplification of intron II allowed us to identify the sweet cherry genotypes carrying $\mathrm{S}_{2}, \mathrm{~S}_{3}, \mathrm{~S}_{4}, \mathrm{~S}_{5}, \mathrm{~S}_{6}, \mathrm{~S}_{7}, \mathrm{~S}_{9}$ but discrimination of $\mathrm{S}_{1}$ from $\mathrm{S}_{13}$ and $\mathrm{S}_{10}$ from $\mathrm{S}_{14}$ required additional analysis (Table 1). With PaConsII consensus primer pair, $\mathrm{S}_{1}$ and $\mathrm{S}_{13}$ alleles had the same size of DNA fragment amplified and the sizes of amplified DNA fragments for $\mathrm{S}_{10}$ and $\mathrm{S}_{14}$ alleles were too close to discriminate them on an agarose gel (Sonneveld et al., 2001, 2003). In order to verify S-allele combinations of local Turkish sweet cherry genotypes determined by consensus primers, the S-RNase gene of each local sweet cherry genotype was amplified using $\mathrm{S}$-allele $\left(\mathrm{S}_{1}-\mathrm{S}_{16}\right)$-specific primer pairs developed by Sonneveld et al. (2001, 2003) (Figure 1). The S-allele combination of each local Turkish sweet cherry genotype was concluded after combining the results of consensus and S-allele-specific primer pairs (Table 1). 
A. Ipek et al.

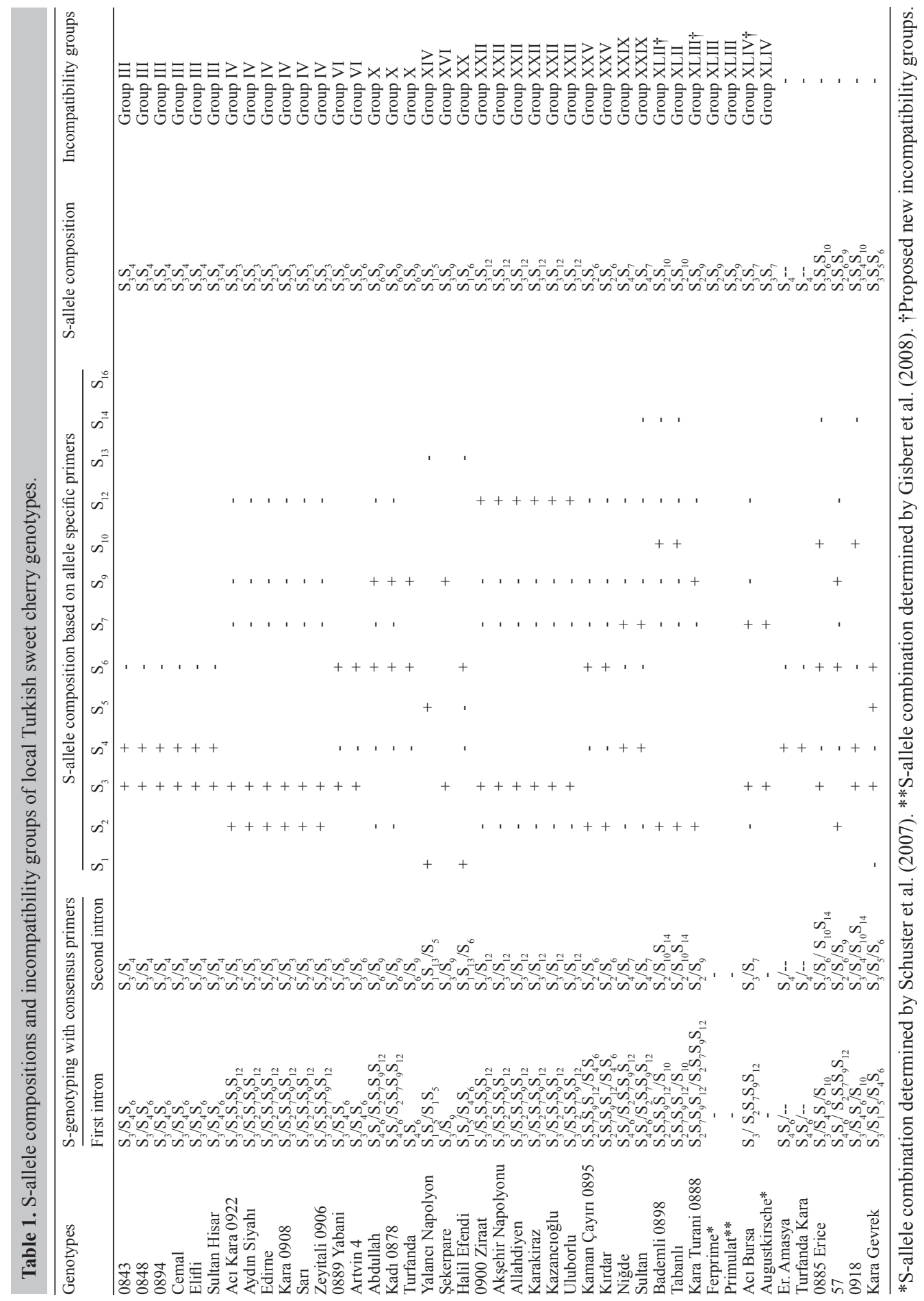

Genetics and Molecular Research 10 (1): 253-260 (2011) 


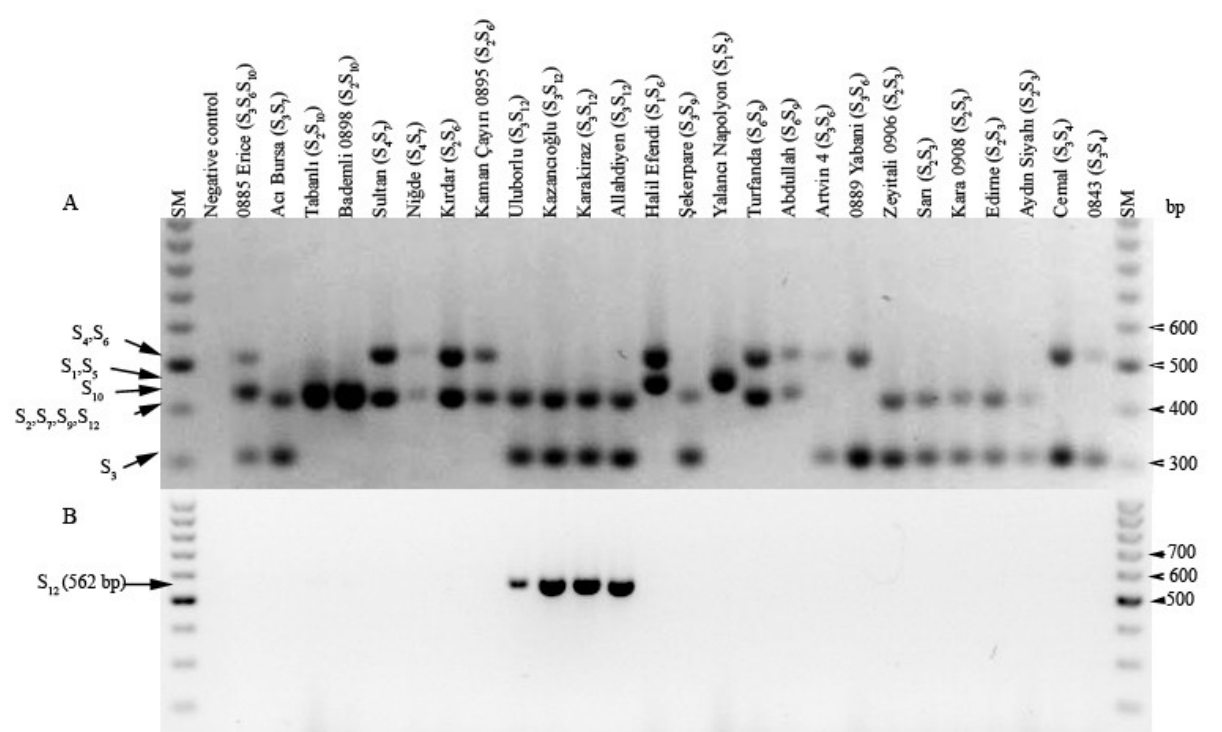

Figure 1. Polymerase chain reaction (PCR) amplification of alleles of S-RNAse in 26 local Turkish sweet cherry genotypes. A. With consensus primer pair for intron I. B. With an S-allele specific primer for the $\mathrm{S}_{12}$ allele. $\mathrm{SM}=$ DNA molecular weight markers (100-bp ladder). Water was added to PCR for negative control.

S-genotyping of 40 local Turkish sweet cherry genotypes allowed detection of 10 different S-alleles; $\mathrm{S}_{1}, \mathrm{~S}_{2}, \mathrm{~S}_{3}, \mathrm{~S}_{4}, \mathrm{~S}_{5}, \mathrm{~S}_{6}, \mathrm{~S}_{7}, \mathrm{~S}_{9}, \mathrm{~S}_{10}$, and $\mathrm{S}_{12}$ (Table 1; Figure 1). Although these genotypes were also screened with primer pairs developed for detecting $\mathrm{S}_{13}, \mathrm{~S}_{14}$ and $\mathrm{S}_{16}$ alleles, the presence of these alleles was not observed. There were two alleles amplified in 36 local Turkish sweet cherry genotypes. However, in four genotypes, '57', '0918', 'Kara Gevrek', and '0885 Erice', three alleles were amplified suggesting that these genotypes were triploid or S-locus was duplicated (Table 1; Figure 1). In another study, De Cuyper et al. (2005) detected the presence of a triploid genotype in Belgian wild cherry genotypes.

A 381-bp DNA fragment was amplified with consensus primers for intron I in 'Er. Amasya 0849' and 'Turfanda Kara' (data not shown). After cloning and sequencing the 381bp DNA fragment, the nucleotide sequence of this DNA fragment was blasted against the sequences in GenBank using the BLASTN program at NCBI (Zhang et al., 2000) and matched with the sequences of the $\mathrm{S}_{4}$ allele of sweet cherry with over $90 \%$ identity (data not shown). There were deletions and insertions and single-nucleotide polymorphisms in the coding region of this allele compared to the S4 allele. However, we were unable to amplify this new allele with consensus primer pair for the amplification of intron II. This new allele of S-RNase has to be further characterized before it can be added as a new sweet cherry S-allele to the literature.

Tobutt et al. (2004) compiled the S-genotypes of some 222 self-incompatible and 25 self-compatible cultivars of cherry using data from previous study on S-genotyping. The allele frequencies of $\mathrm{S}_{1}, \mathrm{~S}_{2}, \mathrm{~S}_{3}, \mathrm{~S}_{4}, \mathrm{~S}_{5}, \mathrm{~S}_{6}$, and $\mathrm{S}_{9}$ were $21,13,29,15,7,11$, and $6 \%$, respectively (Lacis et al., 2008). In our study, the frequencies of $\mathrm{S}_{2}(14.8 \%), \mathrm{S}_{3}(29.6 \%), \mathrm{S}_{4}(13.6 \%), \mathrm{S}_{6}$ (11.1\%), and $\mathrm{S}_{9}(7.5 \%)$ were similar to those published by Tobutt et al. (2004) although occurrences of $\mathrm{S}_{1}(2.5 \%)$ and $\mathrm{S}_{5}(4.9 \%)$ were lower and frequencies of $\mathrm{S}_{7}(3.7 \%)$ and $\mathrm{S}_{10}(4.9 \%)$ were higher in local Turkish sweet cherry genotypes (Figure 2). 


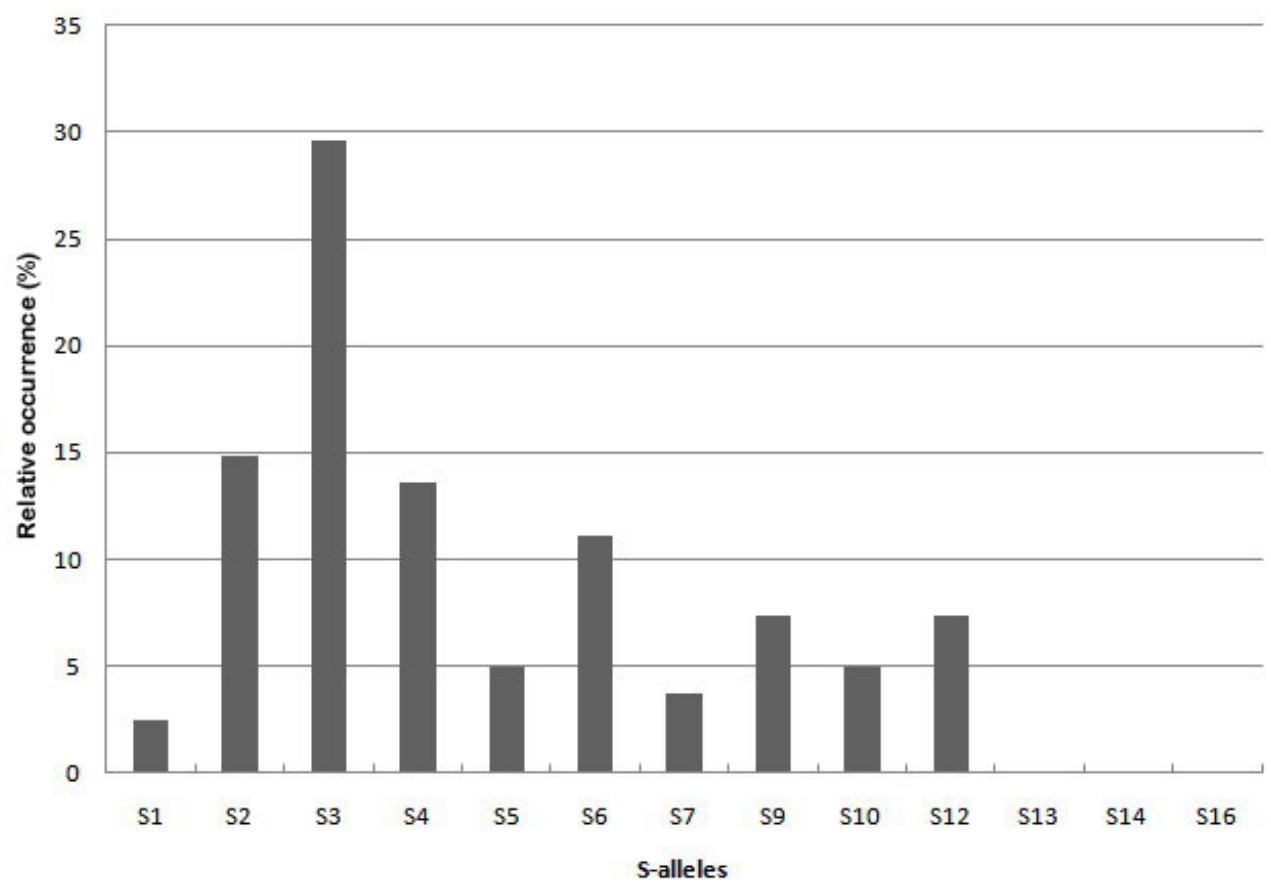

Figure 2. Frequency of S-alleles in local Turkish sweet cherry genotypes.

The $\mathrm{S}_{12}$ allele was quite common in Turkish genotypes, with $7.4 \%$, although it was a very rare allele in the western sweet cherry genotypes (Tobutt et al., 2004). '0900 Ziraat', the most common cultivated Turkish sweet cherry cultivar, has an S-allele composition of $\mathrm{S}_{3} \mathrm{~S}_{12}$; therefore, introduced (foreign origin) sweet cherry cultivars have been successfully used as pollinators for ' 0900 Ziraat' in sweet cherry orchards in Turkey. Lynn E. Long, an Oregon State University Extension Horticulturist, compared '0900 Ziraat' and 'Schneiders', and suggested that '0900 Ziraat' and 'Schneiders' are the same genotypes since both cultivars have similar morphological characteristics and carry the rare S-allele $S_{12}$ (Long, 2006). The author indicated that the $S_{12}$ allele was present in only two cherries out of over 200 western sweet cherry genotypes examined. In our study, however, 6 of 40 Turkish cultivars had allelic combination of $\mathrm{S}_{3} \mathrm{~S}_{12}$, suggesting that $\mathrm{S}_{12}$ is not a very rare allele in Turkish sweet cherry genotypes. Therefore, we suggest using DNA molecular markers, such as SSR or AFLP, for better estimation of the genetic relationship between ' 0900 Ziraat' and 'Schneiders'.

After determination of S-allele compositions, 30 local Turkish sweet cherry genotypes were assigned to 10 previously determined incompatibility groups (Table 1). Most common incompatibility groups were Group III, Group IV and Group XXII with 6 genotypes in each. There was no previously assigned incompatibility group for the S-allele combination of remaining genotypes. A new incompatibility group, XLII, was assigned for 'Bademli 0898' and 'Tabanlı' containing $\mathrm{S}_{2} \mathrm{~S}_{10}$ alleles. The remaining four cultivars, 'Kara Turani 0888 ' $\left(\mathrm{S}_{2} \mathrm{~S}_{9}\right)$ and 'Ac1 Bursa' $\left(\mathrm{S}_{3} \mathrm{~S}_{7}\right)$, have unique $\mathrm{S}$-allele combinations and there were no previously determined incompatibility groups. Previous studies reported that 'Ferprime' and 'Primulat' have the same S-alleles as 'Kara Turani 0888' ( $\left.\mathrm{S}_{2} \mathrm{~S}_{9}\right)$ (Schuster et al., 2007; Gisbert et al., 2008). Similarly, 'Ac1 Bursa' 
and 'Augustkirsche' (Schuster et al., 2007) have the same allelic combination of $\mathrm{S}_{3} \mathrm{~S}_{7}$. Therefore, incompatibility group XLIII was allocated for 'Kara Turani 0888', 'Ferprime', and 'Primulat'. Another incompatibility group, XLIV, was assigned for 'Ac1 Bursa' and 'Augustkirsche'. Genotypes carrying a new S-allele or triploid S-alleles were not assigned to incompatibility groups.

S-allele combinations of western sweet cherry germplasm and sweet cherry genotypes from the breeding programs in Europe, Canada and the U.S. have previously been determined (Wiersma et al., 2001; Sonneveld et al., 2001, 2003; Tobutt et al., 2001, 2004; De Cuyper et al., 2005; Schuster et al., 2007; Marchese et al., 2007; Gisbert et al., 2008; Lacis et al., 2008; Stanys et al., 2008). These studies on the S-genotyping of sweet cherry assigned the sweet cherry genotypes to various incompatibility groups, which is useful for both sweet cherry growers and breeders. Tobutt et al. (2004) compiled the cherry S-genotyping data and determined 26 incompatibility groups. Schuster et al. (2007) extended it to 35 after S-genotyping sweet cherry accessions and cultivars in the German Fruit Gene Bank and private collections. With recent studies on the S-genotyping of sweet cherry genotypes by Marchese et al. (2007), Gisbert et al. (2008) and Stanys et al. (2008), the number of incompatibility groups has reached 41. Our results from the S-genotyping of 35 Turkish sweet cherry genotypes suggested additional three incompatibility groups and we proposed incompatibility groups XLII, XLIII and XLIV. These results indicated that the number of incompatibility groups will increase in the future with the S-genotyping of more sweet cherry genotypes from eastern origin and with the discovery of new S-alleles. This will make following incompatibility groups more complicated. On the other hand, establishment of a public data base containing information on the incompatibility groups of sweet cherry genotypes examined can serve the sweet cherry community by finding incompatibility groups of sweet cherry genotypes and cultivars of interest.

Information obtained from this study on S-allele combinations of local Turkish sweet cherry genotypes will be useful during the establishment of new commercial sweet cherry orchards. In order to maximize the fruit set and consequently yield, choosing the correct pollinator(s) for the main cultivar(s) of an orchard is very important and this information will help in making the correct pollinator choice in Turkey. For example, '0900 Ziraat' and 'Aksehir Napolyonu' are two common cultivars grown in Turkey. We found that these two cultivars are in the same incompatibility group, since both possess $\mathrm{S}_{3} \mathrm{~S}_{12}$ alleles. Sweet cherry orchards established using these two cultivars will not have satisfactory fruit set due to the lack of an appropriate pollinator. Similarly, Sutyemez and Eti (1999) cross-pollinated '0900 Ziraat' and 'Aksehir Napolyonu' by hand but satisfactory fruit set was not observed, confirming our study on S-allele genotyping. In addition, this information will also be valuable for sweet cherry breeders during the planning of specific crosses in their breeding programs.

\section{ACKNOWLEDGMENTS}

The authors wish to thank the Uludag University Commission of Scientific Research Projects for their financial support of this study through project \#Z-2006/36.

\section{REFERENCES}

Boskovic R and Tobutt KR (1996). Correlation of stylar ribonuclease zymograms with incompatibility alleles in sweet cherry. Euphytica 90: 245-250. 
Boskovic R, Russell K and Tobutt KR (1997). Inheritance of stylar ribonucleases in cherry progenies, and reassignment of incompatibility alleles to two incompatibility groups. Euphytica 95: 221-228.

Crane MB and Lawrence WJC (1929). Genetical and cytological aspects of incompatibility and sterility in cultivated fruits. J. Pomol. Hortic. Sci. 7: 276-301.

De Cuyper B, Sonneveld T and Tobutt KR (2005). Determining self-incompatibility genotypes in Belgian wild cherries. Mol. Ecol. 14: 945-955.

FAO (Food and Agriculture Organization of the United Nations) (2007). Food and Agriculture Organization of the United Nations. Available at [www.fao.org]. Accessed March 9, 2010.

Futterer J, Gisel A, Iglesias V, Kloti A, et al. (1995). Standard Molecular Techniques for the Analysis of Transgenic Plants. In: Gene Transfer to Plants (Potrykus I and Spangenberg G, eds.). Springer-Verlag, New York, 215-218.

Gisbert AD, Badenes ML, Tobutt KR, Llacer G, et al. (2008). Determination of the S-allele composition of sweet cherry (Prunus avium L.) cultivars grown in the southeast of Spain by PCR analysis. J. Hortic. Sci. Biotechnol. 83: 246-252.

Gulen H, Ipek A, Burak M and Eris A (2008). Assessment of genetic diversity and relationships among some sweet cherry cultivars using AFLP ${ }^{\mathrm{TM}}$ markers. Acta Hortic. 795: 127-130.

Gulen H, Ipek A, Ergin S, Akcay ME, et al. (2010). Assessment of genetic relationships among 29 introduced and 49 local sweet cherry accessions in Turkey using AFLP and SSR marker. J. Hortic. Sci. Biotechnol. 85: 427-431.

Lacis G, Kaufmane E, Rashal I, Trajkovski V, et al. (2008). Identification of self-incompatibility $(S)$ alleles in Latvian and Swedish sweet cherry genetic resources collections by PCR based typing. Euphytica 160: 155-163.

Long LE (2006). Turkish Cherries or a Rose by Any Other Name. Available at [http://extension.oregonstate.edu/wasco/ horticulture/Cultivars/documents/TurkishCherries06.pdf]. Accessed March 9, 2010.

Marchese A, Tobutt KR, Raimondo A, Motisi A, et al. (2007). Morphological characteristics, microsatellite fingerprinting and determination of incompatibility genotypes of Sicilian sweet cherry cultivars. J. Hortic. Sci. Biotechnol. 82: 41-48.

Schuster M, Flachowsky H and Kohler D (2007). Determination of self-incompatible genotypes in sweet cherry (Prunus avium L.) accessions and cultivars of the German Fruit Gene Bank and from private collections. Plant Breed. 126: 533-540.

Sonneveld T, Robbins TP, Boskovic R and Tobutt KR (2001). Cloning of six cherry self-incompatibility alleles and development of allele-specific PCR detection. Theor. Appl. Genet. 102: 1046-1055.

Sonneveld T, Tobutt KR and Robbins TP (2003). Allele-specific PCR detection of sweet cherry self-incompatibility $(S)$ alleles S1 to S16 using consensus and allele-specific primers. Theor. Appl. Genet. 107: 1059-1070.

Stanys V, Stanyte R, Staniene G and Vinskiene J (2008). S-allele identification by PCR analysis in Lithuanian sweet cherries. Biologija 54: 22-26.

Sutyemez M and Eti S (1999). Investigations on the fertilization biology of some sweet cherry varieties grown in Pozant1 ecological conditions. Turk. J. Agr. Forest. 23: 265-272.

Tao R, Yamane H, Sugiura A, Murayama H, et al. (1999). Molecular typing of S-alleles through identification, characterization and cDNA cloning for S-RNases in sweet cherry. J. Am. Soc. Hortic. Sci. 124: 224-233.

Tobutt KR, Sonneveld T and Boskovic R (2001). Cherry (in)compatibility genotypes - harmonization of recent results from UK, Canada, Germany, Japan and USA. EUCARPIA Fruit Breed. Sect. Newsl. 5: 41-46.

Tobutt KR, Sonneveld T, Bekefi Z and Boskovic R (2004). Cherry (in)compatibility genotypes - an updated cultivar table. Acta Hortic. 663: 667-671.

Ushijima K, Sassa H, Tao R, Yamane H, et al. (1998). Cloning and characterization of cDNAs encoding S-RNases from almond (Prunus dulcis): primary structural features and sequence diversity of the S-RNases in Rosaceae. Mol. Gen. Genet. 260: 261-268.

Watkins R (1976). Cherry, Plum, Peach, Apricot and Almond. In: Evolution of Crop Plants (Simmonds NW, ed.). Longman, London, New York, 242-247.

Wiersma PA, Wu Z, Zhou L, Hampson C, et al. (2001). Identification of new self-incompatibility alleles in sweet cherry (Prunus avium L.) and clarification of incompatibility groups by PCR and sequencing analysis. Theor. Appl. Genet. 102: 700-708.

Wunsch A and Hormaza JI (2004). S-allele identification by PCR analysis in sweet cherry cultivars. Plant Breed. 123: 327-331.

Zhang Z, Schwartz S, Wagner L and Miller W (2000). A greedy algorithm for aligning DNA sequences. J. Comput. Biol. 7: 203-214. 